DOI: $10.17805 /$ zpu.2015.4.13

\title{
Осмысление мировоззренческого кризиса начала XX века в творчестве Г. Гессе и русских религиозных философов
}

\author{
Н. В. РОЖКОВА \\ (ОРЛОВСКИЙ ГОСУДАРСТВЕННЫЙ АГРАРНЫЙ УНИВЕРСИТЕТ)
}

В условиях глобализации человечество поставлено перед необходимостью сближения, универсализации форм духовной культуры при сохранении национальной и этнической самобытности. Целью данного исследования является выявление сходных проблем, перед решением которых в первой половине XX в. оказались народы России и Германии. Герменевтический анализ произведений немецкого писателя Г. Гессе и русских религиозных философов (С. Л. Франка, И. А. Ильина, С. Н. Булгакова) позволил сделать выводы о сходстве процессов, происходивших в двух национальных культурах.

Анализ текстов художественных произведений Г. Гессе и философского наследия И. А. Ильина, С. Н. Булгакова, С. Л. Франка позволяет выявить сходство проблематики, идейно-тематический параллелизм, свидетельствующие о сходных состояниях русской и немецкой культур в первой половине XX в. Смена культурно-исторической парадигмы, сопровождавшаяся отказом от традиционных для христианства ценностей, вызывала у представителей интеллигенции России и Германии мироощущения пустоты, дисбаланса духовных сил и потребностей личности. Выявление новых источников и оснований духовной деятельности немецкий писатель и русские философы связывают с развитием индивидуальности, творческого потенциала человека, его стремлением к прекрасному, возвышенному, преодолением духовной слабости и равнодушия.

Мировоззренческие поиски Г. Гессе и русских религиозных философов были обусловлены наличием общих основ их миропонимания и общностью проблем, в решение которых были вовлечены лучшие представители национальных культур обеих стран. Так, сущность искусства представителям обеих культур виделась как попытка преодоления бренности бытия, приобщение к вечным ценностям, один из путей воссоединения божественного и земного миров. 
Ключевые слова: русская философия; немецкая культура; Г. Гессе; С. Л. Франк; И. А. Ильин; С. Н. Булгаков; начало XX века

\section{ВВЕАЕНИЕ}

$\Gamma$ лобальные проблемы поставили человечество перед необходимостью искать и находить пути сближения, точки совпадений и пересечений при сохранении необходимой степени самобытности. Войны, конфликты, кризисы возникают именно по причине «неосведомленности» людей об общности волнующих их проблем, сходстве взглядов, универсальности жизненных циклов. Различия тем чаще становятся источником столкновений между народами, чем меньше эти народы знают друг о друге. Очень показательны в этом отношении пути, которыми шли в XX в. культура России и культура Германии. История отношений двух стран во всех проявлениях политических, военных, экономических - полна загадок, недоразумений и трагедий, кульминацией которых стал XX век. Не меньше в этой истории взлетов и открытий, достойных восхищения, но есть и примеры удивительного параллелизма, свидетельствующего о сущностной близости культур двух стран, внесших в копилку мировой культуры существенный вклад. Изучение творчества Германа Гессе в контексте социокультурных процессов первой половины ХХ в. позволяет выделить ряд схожих проблем и идейно-тематических оснований, сближающих русскую и немецкую культуры этого периода. В то время как народы двух великих европейских стран дышали разным «политическим» воздухом, лучшие представители интеллигенции размышляли о сходных проблемах, что подтверждает текстуальный анализ их произведений.

В задачи данного исследования входит сравнительная характеристика проблематики творческого наследия русских религиозных философов начала XX в. и немецкого писателя Г. Гессе, а также интерпретация причин идейно-тематического параллелизма в творчестве представителей двух культур. Эта ситуация весьма интересна тем, что о взаимовлиянии Г. Гессе, с одной стороны, и С. А. Франка, И. А. Ильина, С. Н. Булгакова - с другой, говорить вряд ли возможно: в фундаментальных исследованиях творчества писателя, его переписке и свидетельствах современников отсутствуют упоминания о том, что немецкий классик был знаком с работами русских религиозных философов. Отсутствие интертекстуальных взаимодействий тем не менее не исключило возникновения общих для представителей разных национальных культур подходов к осмыслению проблемы бытия культуры в кризисных состояниях.

Исследования творчества Г. Гессе в СССР и на постсоветском пространстве весьма разнообразны по проблематике и посвящены как интерпретации отдельных произведений писателя, осмыслению отдельных этапов его творчества, так и исследованию сквозных проблем. В рамках данного исследования отметим, что проблема идейно-тематического параллелизма между творчеством представителей русской национальной культуры и творчеством Г. Гессе ранее не рассматривалась.

\section{СУЩНОСТЬ И ФОРМЫ ПРОЯВАЕНИЯ МИРОВОЗЗРЕНЧЕСКОГО КРИЗИСА НАЧААА ХХ ВЕКА}

Выделим темы и подходы, которые волнуют деятелей двух культур - русской и немецкой. Это прежде всего состояние культуры на рубеже XIX-XX вв. и тесно связанное с ним состояние человеческого духа, проблема сущности искусства и механизмов творческой деятельности. 
При характеристике состояния культуры начала XX в. используют термины «кризис», «закат», «декаданс». Так, Г. Гессе пишет о трагедии культуры как о трагедии выхода за рамки доминировавшего длительное время христианского мировоззрения (см. «Фауст и Заратустра. Аоклад, сделанный в бременской местной группе Германского союза монистов 1 мая 1909 года» - Гессе, 2001: 5-30). Ценностно-смысловой потенциал христианства на рубеже XIX-XX вв. переживается как исчерпанный, осмысленный в полной мере. Культура подходит к порогу самообновления, что воспринимается носителями как ее закат. Религиозное мировоззрение оказывается недостаточным для решения всех социально-психологических задач, с которыми сталкивается человек в новых условиях.

Путь духовных исканий, пройденный немецким писателем, удивительно, но закономерно параллелен пути, пройденному русскими религиозными философами на рубеже веков, в частности С. $\Lambda$. Франком. Представляется возможным выделить несколько причин идейно-тематического параллелизма, наблюдаемого в творчестве Г. Гессе и русских религиозных философов начала XX в. (имея в виду наследие И. А. Ильина, С. Н. Булгакова и С. А. Франка). Наиболее важными из этих причин, на мой взгляА, являются:

- наличие общих мировоззренческих основ;

- сходные состояния национальных культур, общность процессов и проблем, в которые вовлечены представители интеллигенции.

Характеризуя состояние европейской культуры в начале XX в., Г. А. Тиме пишет о «сломе всех идентичностей»: «Эпоха, когда говоря словами $A$. Мережковского, человек встретил богочеловека, Аполлон - Христа, а Ницше прямо провозгласил “смерть Бога", неизбежно стала восприниматься как “обезбоженная"; место веры заняло историческое и психологическое исследование мифов (М. Хайдеггер)» (Тиме, 2011: 20-21). Преодоление обществом рамок традиционного христианского мировоззрения, ориентация на дичную и творческую свободу, переоценка морально-нравственных ценностей, поиски новых смыслов приводят к новому ощущению жизни, которое С. $\Lambda$. Франк описывает в работе «Крушение кумиров»: «...мы висим в воздухе над бездной, ибо утеряли внутреннюю связь нашего духа, нашей дичности с бытием, и мы хотим восстановить эту связь, опереться на твердую духовную почву» (Франк, 1990: 163). Эти строки написаны в 1923 г. как результат глубочайшей, последовательной до болезненности рефлексии над недавним опытом социально-исторических поисков русской интеллигенции. Развенчивая кумиры революции, политики, культуры, морали, служения общественному благу и народу, С. $\Lambda$. Франк указывает на развращающую опасность служения высоким идеалам, если они не соответствуют глубинным потребностям личности. А в 1927 г. опубликован один из самых известных романов Г. Гессе «Степной волк», на страницах которого описано состояние человека в условиях кризиса культуры. Аушевная боль, бесприютность и беззащитность, ад борьбы за свободу, который приводит к еще большему одиночеству, постоянный разлад с самим собой - все эти болезни века описаны Г. Гессе, но могут быть отнесены и к состоянию русского общества. Аексические совпадения в описаниях раскрывают близость мироощущений представителей двух культур. «Мы выпали из природы и висим в пустоте», - пишет Гессе (Гессе, 2004: 162). «Мы висим в воздухе среди какой-то пустоты или среди тумана», - пишет Франк (Франк, 1990: 144).

При всей разности ментальности и культурно-исторического опыта русских и немецких деятелей культуры совпадение мироощущения не может быть случайным: от- 
рыв от ортодоксальной религиозной традиции переживается именно как отсутствие твердой почвы под ногами, как пустота души, жаждущей новых идеалов, ценностей и целей. Человек, повисший над бездной неверия или мучительных сомнений, ищет выход из сложившейся ситуации. Зыбкость социально значимых ориентиров приводит на единственно возможный путь веры в собственные силы. «Мы должны искать мужества и веры в себе самих», - считает С. $\Lambda$. Франк (там же), указывая на то, что отказ от прежних идеалов и символов веры не есть предательство, а признак острой потребности в новой вере, новых ценностях и смыслах. Г. Гессе в своих произведениях отстаивал значимость индивидуального, выступал как противник массовости, безличия, мещанства и стандартности. Поиски самого себя, своей сущности, самости, путешествие к ядру собственной личности были предметом размышлений писателя на протяжении всей творческой деятельности. В годы испытаний личных и социальных он находит главную о пору в самом себе, своих гуманистических, альтруистических убеждениях, явно диссонирующих с историческими реалиями первой половины ХХ в.

Опора на собственное «я» имеет у С. $\Lambda$. Франка и Г. Гессе общую причину. Оба автора убеждены в существовании высшей реальности, Бога, всеобщих вневременных нравственных принципов. Изучение глубин собственного «я» неизбежно приведет к тому, что все это будет обнаружено, «...нужно только внимательно вглядеться в свою собственную душу и суметь ощутить даже только свою собственную тоску и неудовлетворенность как обнаружение новой глубочайшей онтологической реальности в последних недрах собственного духа, чтобы непосредственно убедиться, что предмет наших исканий - не призрак, а подлинная реальность, и не нечто далекое и недостижимое, а нечто бесконечно близкое нам, вечно при нас находящееся: ибо тот вечный источник жизни и света, которого мы ищем, - он-то сал и есть та сила, которая гонит нас на поиски его» (курсив автора. - Н. Р.; там же: 170).

Аля Германа Гессе понятия «Бог», «дух», «всеобщее творческое начало» являются синонимичными. В одних произведениях он пишет, что можно «увидеть Бога за работой» (Гессе, 2004: 37), в других размышляет о вечно возобновляющем свои творческие поиски, вечно самообновляющемся Аухе (Гессе, 2004: 347; 1990: 168). Это вполне закономерно, если учесть важнейшие фундаментальные составляющие его мировоззрения: протестантские взгляды родителей и философская система Г. Ф. В. Гегеля, творчеством которого Гессе увлекался долгие годы.

Состояние культуры выражается во множестве мельчайших проявлений как на повседневно-бытовом уровне, так и на уровне эстетических, политических, экономических тенденций. Аучшие представители европейских национальных культур размышляли над проблемой сущности искусства и творческой деятельности.

Обратимся к статье И. А. Ильина «Что такое искусство?» (1937), отличающейся афористичностью и манифестарностью слога. Критикуя искусство, полное «душевного зуда и произвольных выдумок», русский мыслитель подчеркивает, что великие произведения искусства рождаются в процессе добровольного и вдохновенного служения высшим целям и ценностям. И. А. Ильин не принимает модной вседозволенности в искусстве и утверждает, что через искусство «про-рекает себя Богом созданная сущность мира и человека». В глубине души художника зарождается и вызревает «...это Главное, это Сказуемое, этот прорекающийся отрывок мирового смысла, ради которого и творится все художественное произведение» (Ильин, 1993: 243), сама воплощенная Тайна бытия предстает в истинном произведении искусства. Характерная Аля искусства конца XIX - начала XX в. экзальтированная эмоциональность, увлече- 
ние внешними эффектами делают невозможным прикосновение к истинной радости, которая «родится из страдания и одоления» и неразрывно связана со служением как особым способом жизни.

В чем сущность искусства? Кому и чему стоит служить одаренному человеку? Как соотносятся в искусстве содержание и форма? Над этими и другими вопросами Г. Гессе размышляет примерно в то же время, что и русский мыслитель. Он осознает двойственность эмоционально-эстетического отношения к жизни, его превосходство и ограниченность, отводя искусству особую роль в движении культуры. В романе «Нарцисс и Гольдмунд» (1930) творчество показано как служение, требующее безоговорочного отказа от наслаждений, личных желаний, потому что искусство, «такое, казалось бы, духовное божество, требовало стольких ничтожных вещей!» (Гессе, 1994: 145), как крыша над головой, инструменты и материалы, труд и неимоверное терпение. А в повести «Росхальде» (1914) писатель с горечью отрицательно отвечает на вопрос о возможности совмещать творческую деятельность и гармоничную семейную жизнь (Гессе, 2011). Г. Гессе, переживший кризис и крушение брака, душевную болезнь жены, изливает тягостные переживания в повести о несчастном художнике.

Г. Гессе признавал величайшую роль искусства и творческой деятельности вообще, при этом он неоднократно писал о специфике эстетического взгляда на жизнь, некоторой его одномерности. Безусловно, искусство - прорыв к вечности, к великому Ауху, выход в особое бытие. Писатель подчеркивал, что возможности познания мира эстетическим путем ограничены. Художник Гольдмунд, один из главных персонажей повести «Нарцисс и Гольдмунд», на пороге смерти заглянул в лицо вечной женственности - Майи, жизни - смерти, матери, носительницы творческого начала. В произведении искусства не может быть воплощена тайна бытия, потому что сама жизнь противится этому: «...она не хочет, чтобы я сделал ее тайну видимой. Ей больше хочется, чтобы я умер. Я умру охотно, она мне поможет» (Гессе, 1994: 264). Таким образом, существо природы к самовыражению в символической форме и одновременно стремится скрыть свою суть. Искусство открывает нам великую возможность: «...неисполнимые мечты исполнить в грезе, неисполнимые требования исполнить в поэзии, - короче, нелепости жизни обратить в победы духа» (Гессе, 1987: 191).

Одна из точек «сопереживания» русского религиозного философа С. Н. Булгакова и великого немецкого писателя Г. Гессе - это проблемы бытия искусства, сущности и механизмов творчества. Оба мыслителя отводят искусству неизмеримо высокую роль в жизни человека: созидание прекрасного есть попытка преодоления бренности бытия, приобщение к вечному. Тем не менее Г. Гессе отводит творческую роль человеку, С. Н. Булгаков же убежден что «...само искусство отнюдь не имеет самодовлеющего значения, оно есть лишь путь к обретению красоты» (Булгаков, 1994: 243), оно является орудием спасения мира красотой. Угадывая в искусстве способность прозреть «вселепоту» мира, попытаться приоткрыть ее людям, С. Н. Булгаков почти безжалостен в своем вердикте: искусство не может преобразовать, преобразить мир, но может вскрыть его безобразие.

Разница в оценке роли человека - творца произведения искусства кроется в укорененности каждого мыслителя в своей национальной традиции. Г. Гессе неоднократно заявлял о своей монистической позиции, он исходит из идеи единства мироздания, для него расколотость мира на творца и творение устарела. Взгляд европейца на традиционное христианство - это взгляд критический, опротестовывающий фундаментальные идеи, но не аннулирующий их творческий потенциал. Имеет место некая 
попытка «одомашнивания» христианства, приспособления его к реальности, детерминированная невозможностью реализовать христианский идеал в его полноценном варианте.

Аля С. Н. Булгакова очевидна недостаточность искусства, его несамостоятельность по отношению к идеальной, божественной сфере, свидетельством которой является красота: «Сила искусства не в том, что оно само владеет красотой, но в том, что оно в своих художественных символах обладает ключом, отверзающим эту глубину: a realibus ad realiora! Поэтому истинное произведение искусства не может оставаться замкнутым только в себе, в своей действенности оно зовет к жизни в красоте и пророчественно свидетельствует о ней» (там же: 235). Так как искусство не обладает силой красоты, ему не дано стать «соборным», «вселенским», оно имеет свои «жизненные границы».

Согласны писатель и философ и в оценке назначения искусства. Гессе писал о том, что искусство ни в коем случае не призвано подменять своими иллюзорными красотами реальность, но должно иметь смелость «заглянуть в бездну», даже если она готова разверзнуться под ногами, т. е. посмотреть на жизнь во всех ее проявлениях. С. Н. Булгаков критикует «субъективный идеализм» в искусстве и считает, что художник может превратиться в сирену, завлекающую людей к гибели. Там, где есть «утонченное гурманство», «эстетическая гастрономия», искусство уже отпало от вселенской красоты, не чувствительно к ритмам космического действа, т. е. утрачивает свою сущность. Русский философ и немецкий писатель не допускают для художника возможности бегства от жизни.

Объединяющая двух великих, хотя и разновеликих деятелей культуры идея существования высшей реальности является причиной некоторой близости их взглядов на искусство, которое призвано создавать символы высшей реальности, напоминать о ней, призывать к ней, помогая человеку осмыслить свою жизнь.

Оба мыслителя отстаивают свободу искусства как необходимое условие его бытия, как основание его истинности. Г. Гессе отстаивает право писателя, художника быть свободным от того, что принято называть «злобой дня», от указаний в выборе материала, но не от следования «законам Ауха», которые остаются неизменными, а это предполагает искренность, гуманизм, служение добру и красоте. С. Н. Булгаков не только подчеркивает необходимость для искусства быть свободным от самых почтенных законов и норм, но и от ограничений в самом искусстве (имеются в виду рамки течений, направлений, канонов и т. А.). Раз искусство «не имеет тем, а только знает художественные поводь - точки, на которых загорается луи красоть»» (курсив наш. - Н. Р.), ему предоставляется исключительная, всеобъемлющая свобода. Окостенение искусства, превращение его в образць свидетельствует о его старении, в то время как «автономное, свободное искусство признает одну задачу - служение красоте, знает над собой один закон - веления красоты, верность художественному такту» (там же: 238). Эти смысловые сближения в творчестве деятелей разных национальных культур в первой половине XX в. удивительны в качестве социологических предостережений. Россия и Германия при всей несхожести пережили тяжелейшие периоды истории, когда искусство было политически детерминировано, в значительной мере носило заказной характер, регулировалось извне - и закономерно пришло в кризисное состояние.

Исследуя природу творчества и последовательно занимаясь, немецкий писатель убедился в тесной связи творческих процессов и женского начала. Художник «дрем- 
лет на груди у матери», его творчество питают источники чувственной любви и телесных удовольствий, земная красота при всей ее хрупкости и кратковременности искупает неправоту человеческого бытия, а способность любого человека понять, почувствовать ее делает его настоящим художником. С. Н. Булгаков в статье «Труп красоты» (1914), посвященной творчеству Пикассо, пишет, что «...Женственность, Ауша мира, есть материнское лоно искусства, а вместе и его любовь» (Булгаков, 1993: 530). Безусловно, представления Гессе о сущности женского начала очень далеки от булгаковских: красота, женственность, имеющие метафизический статус, Аля Г. Гессе просто не существуют. Классическая дилемма «дух — природа», прослеживающаяся в его творчестве, при всех попытках отстоять идею единства мира так и не была преодолена. В пользу этого говорят факты из истории литературы: в поздних произведениях немецкого писателя практически нет ни размышлений о любви, ни женских образов, а проблема развития духовности за счет вытеснения, сознательного обуздания инстинктивного, естественного, чувственного приобретает все большее значение. Но при всем әтом одно важнейшее, глубинное сходство роднит мировосприятие философа и писателя, представителей разных народов, разных духовных поколений: для них обоих красота мира абсолютно реальна, несмотря на несовершенства и противоречия мира.

Опора русских философов на православную религиозную традицию придает их позиции основательность, «ибо священные традиции не изживаются никогда!» (Ильин, 1993: 249). Аостижения классического искусства не оспариваются мыслящими и эстетически одаренными людьми, но искусство как «художественная медитация» (выражение И. А. Ильина) не удовлетворяет потребностей человека, заброшенного временем в XX век. Проблема личности, увлеченной самопознанием, становится одной из центральных в философии и искусстве. Г. Гессе внес значительный вклад в разработку этой проблемы в своем художественном, эпистолярном и публицистическом наследии.

При всей близости взглядов русских религиозных философов и немецкого писателя-классика не будем забывать о разнице мировоззренческих основ их творчества. Идея Единого, Совершенного и Вечного Бога предполагает осуществление творчества в определенных рамках, границах; неизменность истин при их кажущейся неисчерпаемости рано или поздно начинает восприниматься как формальное ограничение.

Близость проблемно-тематического поля произведений русских философов и немецкого писателя, творивших в начале прошлого века, вряд ли можно считать совпадением. Как показал приведенный выше анализ, интеллигенция стран, дважды вступавших в мировые войны, ведет поиски в общем направлении, мучается одними нерешенными вопросами. Близость немецкой и русской национальных культур при всем своеобразии проявляется в пересечении проблематики, параллелизме тенденций. Э. Трельч в работе «Метафизический и религиозный дух немецкой культуры» подчеркивает: «Немцы по своей природе метафизики и мыслители, стремящиеся изнутри, из духовной глубины универсума понять сущность мира и вещей, людей и судеб» (Трельч, 1995: 542). Отдавая религиозности первое место в немецком национальном характере, Э. Трельч пишет и о других его особенностях, известных и признаваемых ныне: о трудолюбии, дисциплинированности, о стремлении к исполнению долга. Показательно, что эта статья написана в 1916 г., когда в России религиозными философами делаются попытки обновления, переосмысления христианского вероучения. Приближающиеся мировоззренческие катаклизмы в России не принижают значения 
этих попыток, они лишь ярче оттеняют сущностные потребности национально духа. Безусловно, стремление к обретению вертикальных векторов духовного движения проявляется не только в росте числа религиозно настроенных людей. Современная история России показала, что русскому национальному характеру религиозность присуща в той же, если не в большей степени.

Описанные С. $\Lambda$. Франком кумиры выполняли своеобразную замещающую функцию по отношению к религиозности как таковой на этапе перехода культуры от моноцентрического к полицентрическому типу (подробнее о названных типах культуры см. в работе В. Н. Финогентова: Финогентов, 2009: 266-280). Идеи свободы личности, развития культуры, революционного преобразования социума были для русской интеллигенции путеводной звездой, которая оказалась болотным огоньком, увлекающим к гибели. Характер идеологических кумиров советской и постсоветской эпох не менее ярко демонстрирует потребность русского народа в кумиротворчестве. Немецкая социально-политическая история также полна попыток создания кумиров, бурного поклонения им, болезненного свержения и не менее мучительных поисков новых аксиологически значимых, эмоционально окрашенных ориентиров, универсалий, идей, способных выступать в роли консолидирующего начала для нации. Опыт, приобретаемый социумом в результате кумиротворческой и кумироборческой деятельности, является важным фактором роста национального самосознания, стимулирует рефлексивные процессы в искусстве и философии.

\section{ЗАКАЮЧЕНИЕ}

Близость культур разных народов может проявляться по-разному, существовать в явных и латентных формах. Общность социокультурного контекста может вызывать к жизни сходные идеи, замыслы, суждения в разном воплощении. Межгосударственные войны, экономические трудности, деструктивные процессы в образовании, искусстве, морали являются наиболее яркими показателями кризисного состояния культуры Западной Европы в первой половине XX в. Революция и Гражданская война в России свидетельствовали о переходе к новому типу культуры. Осмысление причин, сущности и путей преодоления этих процессов входило в задачи деятелей культуры. Очевидный параллелизм эстетической, антропологической, социокультурной проблематики в наследии русских религиозных философов и немецкого писателя Г. Гессе свидетельствует о сходстве состояний двух национальных культур на рубеже $\mathrm{XIX}$ и XX вв. Острота и глубина переживаемого двумя народами мировоззренческого кризиса являлись причиной мучительных и плодотворных поисков деятелями культуры и искусства путей его преодоления.

\section{СПИСОК АИТЕРАТУРЫ}

Булгаков, С. Н. (1993) Труп красоты. По поводу картин Пикассо // Булгаков С. Н. Соч. : в 2 т. М. : Наука. Т. 2: Избранные статьи. 752 с. С. 527-545.

Булгаков, С. Н. (1994) Свет невечерний: Созерцания и умозрения. М. : Республика. 415 с.

Гессе, Г. (1987) Письма по кругу : пер. с нем. / сост., авт. предисл. и коммент. В. А. Седельник. М. : Прогресс. 400 с.

Гессе, Г. (1990) Магия книги : пер. с нем. М. : Книга. 238 с.

Гессе, Г. (1994) Нарцисс и Гольдмунд // Гессе Г. Собр. соч. : в 4 т. : пер. с нем. СПб. : Северозапад. Т. 3. 511 с.

Гессе, Г. (2001) Фауст и Заратустра : пер. с нем. СПб. : Азбука. 320 с.

Гессе, Г. (2004) Степной волк : пер. с нем. СПб. : Азбука-классика. 288 с. 
Гессе, Г. (2011) Росхальде : пер с нем. М. : АСТ ; Астрель. 252 с.

Ильин, И. А. (1993) Одинокий художник. История и әстетика в памятниках и документах / сост., предисл. и примеч. В. И. Белова. М. : Искусство. 348 с.

Тиме, Г. А. (2011) Россия и Германия: философский дискурс в русской литературе XIX-XX веков. СПб. : Нестор-История. 456 с.

Трельч, Э. (1995) Метафизический и религиозный дух немецкой культуры // Культурология. ХХ век : антология / гл. ред. и сост. С. Я. Аевит. М. : Юристъ. 703 с. С. 540-556.

Финогентов, В. Н. (2009) Религиозный ренессанс или философия гуманизма? Мировоззренческий выбор современной культуры. М. : Книжный дом «Аиброком». 304 с.

Франк, С. А. (1990) Крушение кумиров // Франк С. А. Соч. М. : Правда. 608 с. С. 111-180.

Аата поступления: 17.02.2015 2.

\begin{abstract}
UNDERSTANDING THE IDEOLOGICAL CRISIS OF THE EARLY 20TH CENTURY
IN THE WORKS OF HERMANN HESSE AND RUSSIAN RELIGIOUS PHILOSOPHERS
\end{abstract}

\title{
N. V. ROZHKOVA
}

(ORYol StATE AGRARIAN UNIVERSITY)

Living under globalization, mankind faces the challenge of rapprochement and of universalizing the forms of spiritual culture while maintaining national and ethnic identity. The lack of knowledge about the ongoing processes in the ethical, aesthetic and educational spheres of society's life can trigger military, political, economic or other conflicts between nations. The aim of this study is to identify the similar problems which the peoples of Russia and Germany faced in the first half of the 20th century. This has been achieved by means of a hermeneutic analysis of the works of German writer Hermann Hesse and Russian religious philosophers (Semyon Frank, Ivan Ilyin, Sergei Bulgakov).

A change of the cultural and historical paradigm, accompanied by the abandonment of traditional Christian values of Christianity, made Russian and German intelligentsia feel global emptiness and an imbalance between spirituality and human needs. Both the German writer and the Russian philosophers looked for new sources and foundations of creative spirituality in the development of human potential, in the pursuit of beauty, of the sublime, and in overcoming spiritual weakness and indifference.

The spiritual quests of Hermann Hesse and Russian religious philosophers were based on similar worldviews and faced similar obstacles, which the best minds of both nations were trying to overcome. They saw the essence of art as an attempt to transcend the frailness of life and partake of eternal values by choosing art as one of the ways to reunite the divine and earthly worlds.

Keywords: Russian philosophy; German culture; Hermann Hesse; S. L. Frank; I. A. Ilyin; S. N. Bulgakov; early 20 th century

\section{REFERENCES}

Bulgakov, S. N. (1993) Trup krasoty. Po povodu kartin Pikasso [Cadaver of the beauty. Regarding Picasso's paintings]. In: Bulgakov, S. N. Socbineniia [Works] : in 2 vols. Moscow, Nauka Publ. Vol. 2: Izbrannye stat' $i$ [Selected articles]. 752 p. Pp. 527-545. (In Russ.). Russ.).

Bulgakov, S. N. (1994) Svet nevecbernii [Unfading light]. Moscow, Respublika Publ. 415 p. (In

Hesse, H. (1987) Pis'ma po krugu [Rundbriefe] : transl. from German / comp., foreword and comment. by V. D. Sedelnik. Moscow, Progress Publ. 400 p. (In Russ.).

Hesse, H. (1990) Magiia knigi [The magic of the book] : transl. from German. Moscow, Kniga Publ. 238 p. (In Russ.).

Hesse, H. (1994) Nartsiss i Gol'dmund [Narcissus and Goldmund]. In: Hesse, H. Sobranie sochinenii [Collected Works] : In 4 vols. / transl. from German. St. Petersburg, Severo-Zapad Publ. Vol. 3. 511 p. (In Russ.).

Hesse, H. (2001) Faust i Zaratustra [Faust and Zarathustra] : transl. from German. St. Petersburg, Azbuka Publ. 320 p. (In Russ.). 

Russ.).

Hesse, H. (2004) Stepnoi volk [Steppenwolf]. St. Petersburg, Azbuka-klassika Publ. 288 p. (In

Hesse, H. (2011) Roskbal' de [Rosshalde]. Moscow, AST Publ. ; Astrel' Publ. 252 p. (In Russ.).

Ilyin, I. A. (1993) Odinokii kbudozhnik. Istoriia i estetika v pamiatnikakb $i$ dokumentakb [A lonely artist. History and aesthetics in monuments and documents] / comp., foreword and notes by V. I. Belov. Moscow, Iskusstvo Publ. 348 p. (In Russ.).

Time, G. A. (2011) Rossiia i Germaniia: filosofskii diskurs v russkoi literature XIX-XX vekov [Russia and Germany: Philosophical discourse in 19th and 20th century Russian literature]. St. Petersburg, Nestor-Istoria Publ. 456 p. (In Russ.).

Troeltsch, E. (1995) Metafizicheskii i religioznyi dukh nemetskoi kul'tury [Metaphysical and religious spirit of German culture]. In: Kul'turologiia. XX vek [Culturology. 20th century] : An anthology / ed. and comp. by S. Ya. Levit. Moscow, Iurist» Publ. 703 p. Pp. 540-556. (In Russ.).

Finogentov, V. N. (2009) Religioznyi renessans ili filosofiia gumanizma? Mirovozzrencheskii vybor sovremennoi kul'tury [Religious renaissance or humanist philosophy? The grand choice of contemporary culture]. Moscow, Librokom Publ. House. 304 p. (In Russ.).

Frank, S. L. (1990) Krushenie kumirov [Collapse of idols]. In: Frank, S. L. Socbineniia [Works]. Moscow, Pravda Publ. 608 p. Pp. 111-180. (In Russ.).

Submission date: 17.02.2015.

Рожкова Наталья Васильевна - кандидат педагогических наук, доцент кафедры философии и истории Орловского государственного аграрного университета. Адрес: 302012, Россия, г. Орел, ул. Генерала Родина, д. 69. Тел.: +7 (486) 270-18-87. Эл. алрес: more-nz@rambler.ru

Rozhkova Natalia Vasilievna, Candidate of Pedagogy, Associate Professor, Department of Philosophy and History, Oryol State Agrarian University. Postal address: 69 Generala Rodina St., 302012 Oryol, Russian Federation. Tel.: +7 (486) 270-18-87. E-mail: more-nz@rambler.ru 